Abanico Veterinario. Enero-Diciembre 2020; 10:1-14. http://dx.doi.org/10.21929/abavet2020.37

Artículo Original. Recibido: 06/07/2020. Aceptado: 26/11/2020. Publicado: 17/12/2020. Clave:2020-57.

\title{
Microbiota vaginal y susceptibilidad quimioterapéutica en cabras criollas
}

\author{
Vaginal microbiota and antimicrobial susceptibility in creole goats
Wilfrido Flores-Hernández ${ }^{\mathrm{ID}}$, Gabriela Luna-Castro ${ }^{\mathrm{ID}}$, Luz Peña-Avelino ${ }^{\mathrm{ID}}$, Hugo Barrios-García ${ }^{\mathrm{ID}}$, Jorge Alva-Pérez ${ }^{\mathrm{ID}}$

Facultad de Medicina Veterinaria "Dr. Norberto Treviño Zapata". Universidad Autónoma de Tamaulipas. Ciudad Victoria, Tamaulipas, México. Autor responsable y de correspondencia: Jorge Alva-Pérez. Carretera Victoria-Mante km 5. CP. 87000, Ciudad Victoria, Tamaulipas, México. wii_09@hotmail.com, sarahi.luna@docentes.uat.edu.mx, lypena@docentes.uat.edu.mx, hbarrios@docentes.uat.edu.mx jalva@docentes.uat.edu.mx

\section{RESUMEN}

El objetivo de este trabajo fue determinar la microbiota vaginal aerobia de cabras criollas, así como el perfil de susceptibilidad a quimioterapéuticos. Se tomaron muestras de mucosa vaginal de 51 hembras caprinas sanas en edad reproductiva mediante hisopos estériles. Las muestras fueron procesadas bajo técnicas de identificación bacteriológica estándar. Se obtuvo aislamiento bacteriano en el $41.2 \%$ de las muestras. Las bacterias aisladas con mayor frecuencia fueron cocos Gram positivos (GP) (65.6\%), los géneros principales identificados fueron Staphylococcus spp. (31.2\%) y Aerococcus spp. (21.9\%). En cuanto a bacterias Gram negativas (GN), los aislamientos correspondieron a Escherichia coli (15.6\%). Del perfil de resistencia a antibióticos los aislamientos de Aerococcus y Corynebacterium jeikeium, en proporción, fueron los más susceptibles a los antibióticos analizados contra bacterias GP. Los antibióticos con menor perfil de resistencia ante aislamientos GP fueron dicloxacilina, cefotaxima y ampicilina. Los aislamientos de $E$. coli mostraron ser altamente resistentes a todos los antibióticos probados (95\%), siendo ciprofloxacina el antibiótico con menor resistencia $(60 \%)$. Los hallazgos de este trabajo ponen de manifiesto la importancia de la microbiota vaginal en cabras criollas como agentes ecológicos con potencial patogénico, además de demostrar la alta resistencia de estas bacterias a agentes quimioterapéuticos.

Palabras clave: producción caprina, microbiota vaginal, susceptibilidad antimicrobiana.

\section{ABSTRACT}

The aim of this work was the aerobic vaginal microbiota determination on creole goats and their antimicrobial susceptibility. Vaginal sample swabs were taken of 51 healthy female goats of reproductive age. Samples were processed under standard bacteriological conditions. Bacterial isolation was achieved in $41.2 \%$ of the samples. Gram-positive (GP) cocci were the most abundant bacteria recovered (65.6\%), the principal genera detected were Staphylococcus spp. (31.2\%) and Aerococcus spp. (21.9\%). Escherichia coli was the only Gram-negative (GN) genus detected. In the antimicrobial susceptibility test, Aerococcus and Corynebacterium jeikeum were the most susceptible GP bacteria. Dicloxacillin, cefotaxime, and ampicillin had the lowest resistance pattern on GP bacteria. On the other hand, E. coli isolate showed high resistance to all antibiotics (95\%), except for ciprofloxacin (60\%). This work's findings exhibit the importance of vaginal microbiota of creole goats as potential pathogenic ecological agents, as well as the high antimicrobial resistance pattern demonstration of these bacteria.

Keywords: goat production, vaginal microbiota, antimicrobial susceptibility. 


\section{INTRODUCCIÓN}

Se denomina microbiota a la población, residente o transitoria, de microorganismos y virus que viven en los epitelios de los animales, creando un ecosistema (Pascale et al., 2018). En este ecosistema los procariontes (bacterias principalmente, aunque también hay arqueas) son los organismos más abundantes. Generalmente, estos microorganismos viven en un estado de simbiosis con el hospedador. Por otro lado, el desbalance del ambiente y del sistema inmune puede desencadenar efectos negativos sobre la salud de los hospedadores, además algunos microorganismos de la microbiota pueden tornarse patógenos (Maynard et al., 2012; Belkaid et al., 2013). En rumiantes es bien conocido el papel de la microbiota ruminal en la digestión de la celulosa, lo que permite la obtención de energía para estos animales (Henderson et al. 2015).

Se ha determinado que la microbiota vaginal (MV) en rumiantes varía conforme el estado fisiológico/reproductivo, ciclo estral y en menor medida por la raza (Giannattasio-Ferraz et al., 2019; Manes et al., 2018). En ovinos y caprinos el análisis de la MV ha cobrado relevancia en los últimos años, debido al uso de tecnologías reproductivas (uso de progestágenos, prostaglandinas y gonadotropinas), principalmente en la ganadería intensiva(Suárez et al., 2006; Martins et al., 2009; Penna et al., 2013; Oliveira et al., 2013; Manes et al., 2013; Manes et al., 2018). Se conoce parcialmente la composición de la MV en cabras; se ha reportado que está compuesta principalmente por bacterias Gram positivas (GP) y en menor medida por Gram negativas (GN) (Manes et al., 2013). En cabras el cambio en la composición de la MV por el uso de dispositivos vaginales que contienen progestágenos se ha vinculado con vaginitis y con infertilidad (Penna et al., 2013).

En México la producción caprina está ligada a las clases sociales con ingresos económicos bajos, siguiendo un modelo primordialmente de subsistencia (PinosRodríguez et al., 2015). En Tamaulipas, México, la producción caprina está dirigida a la producción de cabrito destetado de 21 días de edad. El tipo de producción característico del noreste mexicano es un sistema extensivo dependiente de recursos naturales de la región (Alva-Pérez et al., 2019). Aunque las cabras son animales rústicos, adaptables a diferentes condiciones ambientales, los problemas en la fertilidad y concepción de las cabras son comunes en la producción (Salinas-González et al., 2016). El conocimiento de la MV en cabras criollas puede poner de manifiesto la población bacteriana oportunista, misma que pudiera desencadenar vaginitis clínicas y subclínicas. Este conocimiento puede sentar las bases para determinar el grado de participación de las infecciones del sistema reproductor en los problemas de producción en cabras. Aunado a ello, el conocimiento del perfil de susceptibilidad a quimioterapéuticos de las bacterias que conforman la MV contribuye a mejorar el tratamiento de estas infecciones. 


\section{MATERIAL Y MÉTODOS}

Manejo animal y sitio de muestreo. El presente trabajo se llevó a cabo en el municipio de Jaumave, Tamaulipas localizado entre los paralelos $23^{\circ} 53^{\prime}$ y $23^{\circ} 04^{\prime}$ latitud norte, y los meridianos $99^{\circ} 41^{\prime}$ y $99^{\circ} 10^{\prime}$ longitud oeste, con una altura de $735 \mathrm{msnm}$ promedio. La orografía es principalmente montañosa, con un clima semiseco semicálido con lluvias en verano (INEGI, 2010). El inventario caprino en este municipio reportado en el año 2018 fue de 3,931 cabezas (SIAP, 2019). Se muestrearon cinco unidades de producción (UP) durante junio de 2019. En cada UP se tomaron 10 muestras, a excepción de la última en dónde se tomaron 11 muestras, para un total de 51 muestras de hisopados vaginales. Los hatos caprinos presentan una población que mezcla varias razas (población criolla), con encastes predominantes de Boer, Alpino, Nubia y Toggenbourgh (Alva-Pérez et al., 2019). El criterio de inclusión fue hembras sanas y en edad reproductiva (2 a 4 años). El criterio de exclusión fue hembras enfermas o gestantes. El muestreo fue realizado bajo estándares éticos de bienestar animal, y fue autorizado por el Comité de Bioética y Bienestar Animal de la Facultad de Medicina Veterinaria y Zootecnia de la Universidad Autónoma de Tamaulipas (oficio número CBBA_19_05).

Obtención de muestras y procesamiento. En las hembras seleccionadas se realizó restricción física momentánea con el mínimo estrés posible, para insertar un hisopo estéril en el vestíbulo vaginal. Los hisopos fueron frotados suavemente sobre las paredes de la mucosa vaginal para posteriormente ser colocados en medio de transporte estéril (Dehydrated culture media: transport medium amies; BD Difco, Maryland EU). Los hisopos se conservaron en refrigeración hasta su procesamiento en un periodo no mayor a 12 horas. Todo el procesamiento bacteriológico de las muestras fue llevado a cabo en el Laboratorio de Diagnóstico de la Facultad de Medicina Veterinaria y Zootecnia de la Universidad Autónoma de Tamaulipas. Para el aislamiento e identificación de los microorganismos los hisopos fueron sembrados en agar sangre (Base agar sangre; Becton Dickinson-Bioxon, Querétaro México) y agar tripticaseína de soja (BD Difco, Maryland EU). Las muestras fueron incubadas en condiciones de aerobiosis, $37^{\circ} \mathrm{C}$ durante 24 a 48 horas.

Los diferentes aislamientos fueron identificados tanto macroscópicamente (morfología colonial, producción de pigmento y hemólisis) como microscópicamente (tinción de Gram). La identificación bacteriana final se logró a través de las siguientes pruebas bioquímicas: catalasa (Peróxido de hidrógeno; Merck, Darmstadt Alemania), oxidasa ( $\mathrm{n}$, $\mathrm{n}, \mathrm{n}^{\prime}, \mathrm{n}^{\prime}$-tetrametil-1,4-fenilendiamina, Biomerieux México, Estado de México), rojo de metilo-Voges Proskauer (Becton Dickinson Bioxon, Querétaro México), reducción de nitratos (BD Difco, Maryland EU), ureasa (Caldo urea; Becton Dickinson-Bioxon, Querétaro México), indol, ácido sulfhídrico y motilidad (medio SIM; Dibico, Estado de México México), crecimiento en agar McConkey (BD Difco, Maryland EU), triple azúcar hierro (Agar de hierro y triple azúcar, Becton Dickinson-Bioxon, Querétaro México), citrato 
(BBL Simmons Citrate Agar; Becton Dickinson, Le Point de Claix Francia) y utilización de los siguientes carbohidratos: maltosa, manitol, xilosa, lactosa y sorbitol (todos de Becton Dickinson Bioxon, Querétaro México, preparados con rojo fenol, caldo base rojo de fenol BD Difco, Maryland EU). La identificación se realizó siguiendo los estándares del manual de identificación bacteriana de Cowan y Steel (Barrow y Feltman, 2004).

Susceptibilidad a quimioterapéuticos. Los aislamientos fueron evaluados en diferentes antibióticos, a través del método de difusión en disco (Humphries et al. 2018). Brevemente se describe a continuación. Se seleccionaron 3 UFC de cada aislamiento en cultivo puro, mismas que fueron sembradas en caldo tripticaseína de soya (BD Difco, Maryland EU) e incubadas a $37^{\circ} \mathrm{C}$ en agitación (200 rpm). El tiempo de incubación varió para cada aislamiento, hasta obtener un inóculo equivalente al estándar 0.5 McFarland $\left(0.05 \mathrm{ml}\right.$ de $1 \%$ de $\mathrm{BaCl}_{2}$ [Sigma-Aldrich, St. Louis, Missouri Estados Unidos] y $9.95 \mathrm{ml}$ de $1 \%$ de $\mathrm{H}_{2} \mathrm{SO}_{4}$ [Sigma-Aldrich, St. Louis, Missouri Estados Unidos]) de turbidez, correspondiente a 1 a $2 \times 10^{6} \mathrm{UFC} / \mathrm{ml}$ en bacterias GP y $5 \times 10^{8} \mathrm{UFC} / \mathrm{ml}$ en bacterias GN. Se sembró $1 \mathrm{ml}$ de cada aislamiento en agar Müller-Hinton (MH, BD Difco, Marylando EU). Los siguientes sensidiscos (Investigación Diagnóstica; Ciudad de México, México) fueron utilizados: ampicilina (10 $\mu \mathrm{g}$, Staphylococcus spp.: fenotipo resistente (FR): < $28 \mathrm{~mm}$; fenotipo susceptible (FS): $>29 \mathrm{~mm}$; otros géneros bacterianos: FR: $<21 \mathrm{~mm}$; FS: $>22$ $\mathrm{mm})$, cefalotina $(30 \mu \mathrm{g}, \mathrm{FR}:<14 \mathrm{~mm}, \mathrm{FS}:>15 \mathrm{~mm})$, cefotaxima $(30 \mu \mathrm{g}, \mathrm{FR}:<14 \mathrm{~mm}$, FS: $>15 \mathrm{~mm}$ ), ciprofloxacino ( $5 \mu \mathrm{g}, \mathrm{FR}:<15 \mathrm{~mm}, \mathrm{FS}:>16 \mathrm{~mm})$, clindamicina (30 $\mu \mathrm{g}, \mathrm{FR}$ : $<14 \mathrm{~mm}$, FS: $>15 \mathrm{~mm}$ ), dicloxacilina $(1 \mu \mathrm{g}, \mathrm{FR}:<10 \mathrm{~mm}, \mathrm{FS}:>11 \mathrm{~mm})$, eritromicina (15 $\mu \mathrm{g}$, FR: $<13 \mathrm{~mm}$, FS: $>14 \mathrm{~mm})$, gentamicina $(10 \mu \mathrm{g}$, FR: $<12 \mathrm{~mm}$, FS: $>13 \mathrm{~mm})$, penicilina (10 U, Staphylococcus spp.: FR: < $28 \mathrm{~mm}$, FS: $>29 \mathrm{~mm}$, otros géneros GP: FR: $<14 \mathrm{~mm}$; FS: $>15 \mathrm{~mm}$ ), sulfametoxazol-trimetroprim (25 $\mu$ g, FR: $<10 \mathrm{~mm}$, FS: $>11$ $\mathrm{mm})$, tetraciclina (30 $\mu \mathrm{g}, \mathrm{FR}:<14 \mathrm{~mm}$, FS: $>15 \mathrm{~mm})$, vancomicina $(30 \mu \mathrm{g}, \mathrm{FR}:<14 \mathrm{~mm}$, FS: $>15 \mathrm{~mm}$ ), cloranfenicol (30 $\mu \mathrm{g}$, FR: $<12 \mathrm{~mm}$, FS: $>13 \mathrm{~mm})$, carbenicilina $(100 \mu \mathrm{g}$, FR: < $18 \mathrm{~mm}$, FS: > $19 \mathrm{~mm})$, netilmicina $(30 \mu \mathrm{g}$, FR: < $12 \mathrm{~mm}$, FS: > $13 \mathrm{~mm})$, nitrofurantoína (300 $\mu \mathrm{g}, \mathrm{FR}:<14 \mathrm{~mm}, \mathrm{FS}:>15 \mathrm{~mm})$, norfloxacino $(100 \mu \mathrm{g}, \mathrm{FR}:<18 \mathrm{~mm}$, FS: $>19 \mathrm{~mm}$ ) y amikacina ( $30 \mu \mathrm{g}, \mathrm{FR}:<14 \mathrm{~mm}$, FS: $>15 \mathrm{~mm}$ ). Los quimioterapéuticos clindamicina, dicloxacilina, eritromicina, penicilina, tetraciclina y vancomicina fueron probados únicamente en aislamientos GP; mientras que cloranfenicol, carbenicilina, netilmicina, nitrofurantoína, norfloxacino y amikacina se probaron únicamente en aislamientos GN. Las zonas de inhibición en cada sensidisco se midieron con una regla después de 16 a $18 \mathrm{~h}$ de incubación a $37^{\circ} \mathrm{C}$. Los aislamientos con una susceptibilidad intermedia se consideraron resistentes, ya que estas poblaciones bacterianas presentan subpoblaciones de bacterias resistentes que transmitirán este fenotipo a las bacterias susceptibles (Hombach et al. 2013; Maurer et al. 2014). 
Análisis estadístico. Los resultados de identificación bacteriana de las diferentes muestras se presentan a través de estadística descriptiva y tablas de frecuencia. Para los resultados de la prueba de susceptibilidad a quimioterapéuticos se construyeron tablas de contingencia con la prueba de chi cuadrada con un nivel de significancia de $P$ $<0.05$ mediante el procedimiento de PROC FREQ del programa SAS (2002, v9.0. SAS Institute Inc., Cary, NC., USA) para conocer los porcentajes de resistencia. Además, se realizó un análisis de varianza en un modelo lineal generalizado usando el PROC GLM y la prueba de diferencia mínima significativa (LSD, prueba exacta de Fisher) para la comparación del perfil de resistencia entre antibióticos con una $P<0.05$. Para este análisis se realizó la conversión de los valores porcentuales en valores en un rango de 0 a 1.

\section{RESULTADOS}

Aislamiento e identificación bacteriana. De las 51 muestras únicamente 21 (41.2\%) resultaron positivas al aislamiento bacteriológico. De estas 21 muestras se aislaron e identificaron 32 bacterias (Cuadro 1).

Cuadro 1. Identificación y frecuencia de los aislamientos bacteriológicos de las muestras vaginales de cabras.

\begin{tabular}{lc}
\hline & Frecuencia \\
\hline Bacterias Gram positivas & \\
Staphylococcus spp. & $31.2 \%(10 / 32)$ \\
Aerococcus spp. & $21.9 \%(7 / 32)$ \\
Corynebacterium jeikeium & $15.6 \%(5 / 32)$ \\
Staphylococcus chromogenes & $6.3 \%(2 / 32)$ \\
Corynebacterium renale & $3.1 \%(1 / 32)$ \\
Staphylococcus xylosus & $3.1 \%(1 / 32)$ \\
Streptococcus spp. & $3.1 \%(1 / 32)$ \\
Bacterias Gram negativas & \\
Escherichia coli & \\
\hline
\end{tabular}

Susceptibilidad a quimioterapéuticos. En el análisis del perfil de resistencia antimicrobiana para las bacterias GP es de notar que todas los aislados fueron resistentes a eritromicina y tetraciclina (Cuadro 2). Los aislados de Staphylococcus spp. tuvieron un porcentaje general de resistencia de $87.5 \%\left(\chi^{2}=18.51, p=0.0704\right)$, siendo la penicilina el antibiótico con menor resistencia (70\%). Los dos aislamientos de $S$. chromogenes tuvieron la menor resistencia entre los antibióticos probados $(70.8 \%)$, sin diferencia entre ellos $\left(\chi^{2}=16.73, p=0.1158\right)$. Los aislamientos de $C$. renale, $S$. xylosus y Streptococcus spp. tuvieron porcentajes de resistencia de $83.3 \%\left(\chi^{2}=12.0, p=0.3636\right), 91.7 \%\left(\chi^{2}=12.0\right.$, $\mathrm{p}=0.3636)$ y $83.3 \%\left(\chi^{2}=12.0, p=0.3636\right)$, respectivamente. Por otro lado, los aislamientos del género Aerococcus spp. (resistencia 80.9\%) mostraron una resistencia menor contra 
dicloxacilina (28.6\%, $\left.\chi^{2}=22.85, \mathrm{p}=0.0185\right)$, en comparación con los demás antibióticos. Así mismo, los aislamientos de $C$. jeikeium mostraron un menor porcentaje de resistencia ante cefotaxima y ampicilina ( $20 \%$ y $40 \%$, respectivamente $\left.\chi^{2}=34.9, p<0.001\right)$ en contraste con los demás antibióticos. Para estas bacterias la resistencia fue de $85 \%$. Bajo las condiciones de este trabajo los aislamientos GP tuvieron un perfil de resistencia de $83.2 \%$.

Para las enterobacterias (aislamientos GN) el porcentaje general de resistencia fue del $95 \%$, la mayoría de los antibióticos probados tuvieron una resistencia del 100\%, a excepción de ciprofloxacina (60\%) y nitrofurantoína (80\%), cuyas resistencias fueron menores al resto de los antibióticos $(p<0.05$, cuadro 3$)$.

La comparación entre los perfiles de resistencia muestra que dicloxacilina tuvo mayor efectividad entre las bacterias GP $(0.59$, Cuadro 3$)$, similar al perfil de resistencia de ampicilina (0.63) y cefotaxima (0.77). El promedio general de resistencia para los antibióticos probados contra bacterias GP fue de 0.84 , mientras que el promedio general de resistencia de los antibióticos probados contra bacterias GN fue de 0.95 .

Cuadro 2. Porcentaje de resistencia en aislados vaginales de cabras criollas

\begin{tabular}{llcccccccccccc}
\hline Bacterias & $\mathbf{( n ) \%}$ & \multicolumn{10}{c}{ Quimioterapéutico } \\
\hline Gram + & & AMP & CEF & CFT & CIP & CLI & DIC & ERI & GEN & PEN & STM & TET & VAN \\
Staphylococcus spp. & $(10) 37$ & 80 & 90 & 100 & 80 & 90 & 80 & 100 & 80 & 70 & 100 & 100 & 100 \\
Aerococcus spp. & $(7) 25.9$ & 57.2 & 71.4 & 85.7 & 85.7 & 100 & 28.6 & 100 & 85.7 & 85.7 & 71.4 & 100 & 100 \\
C. jeikeium & $(5) 18.5$ & 40 & 100 & 20 & 100 & 100 & 100 & 100 & 100 & 100 & 100 & 100 & 60 \\
S. chromogenes & $(2) 7.4$ & 50 & 0 & 0 & 100 & 100 & 0 & 100 & 100 & 50 & 100 & 100 & 100 \\
C. renale & $(1) 3.7$ & 0 & 100 & 100 & 100 & 100 & 100 & 100 & 0 & 100 & 100 & 100 & 100 \\
S. xylosus & $(1) 3.7$ & 100 & 100 & 100 & 100 & 0 & 100 & 100 & 100 & 100 & 100 & 100 & 100 \\
Streptococcus spp. & $(1) 3.7$ & 100 & 100 & 100 & 100 & 0 & 100 & 100 & 0 & 100 & 100 & 100 & 100 \\
& & & & & & & & & & & & \\
Gram - & & AMP & CEF & CFT & CIP & CLO & CAR & NET & GEN & NIT & NOT & STM & AMI \\
Escherichia coli & (5) 100 & 100 & 100 & 100 & 60 & 100 & 100 & 100 & 100 & 80 & 100 & 100 & 100 \\
\hline
\end{tabular}

AMP: ampicilina, CEF: cefalotina, CFT: cefotaxima, CIP: ciprofloxacino, CLI: clindamicina, DIC: dicloxacilina, ERI: eritromicina, GEN: gentamicina, PEN: penicilina, STM: sulfametoxazol-trimetroprim, TET: tetraciclina, VAN: vacomicina, CLO: cloranfenicol, CAR: carbenicilina, NET: netilmicina, NIT: nitrofurantoína, NOT: norfloxacino y AMI: amikacina.

\section{DISCUSIÓN}

\section{Aislamiento e identificación bacteriana.}

Las condiciones ambientales de la MV de rumiantes favorecen el desarrollo de una microbiota conforme al desarrollo fisiológico. Esta población no permite, en general, el desarrollo de microorganismos patógenos o saprofíticos (Otero et al., 2000). El comprometimiento de la integridad de la mucosa vaginal, así como las alteraciones de la microbiota, pueden desencadenar infecciones ascendentes del tracto urogenital, 
poniendo en riesgo la salud reproductiva de cabras (Ababneh y Degefa, 2006), vacas (Otero et al., 2000) y ovejas (Sargison et al., 2007).

Cuadro 3. Comparación del patrón de resistencia entre antibióticos

\begin{tabular}{|c|c|c|c|c|c|c|c|c|c|c|c|c|c|}
\hline \multirow[t]{2}{*}{ Bacterias } & \multicolumn{13}{|c|}{ Quimioterapéutico } \\
\hline & AMP & CEF & CFT & CIP & CLI & DIC & ERI & GEN & PEN & STM & TET & VAN & $\begin{array}{l}\text { EEM } \\
(P)\end{array}$ \\
\hline Gram + & $0.63^{\text {cd }}$ & $0.81^{\mathrm{abc}}$ & $0.77^{\mathrm{cd}}$ & $0.85^{\mathrm{ab}}$ & $0.93^{a b}$ & $0.59^{d}$ & $1.0^{\mathrm{a}}$ & $0.81^{\mathrm{abc}}$ & $0.81^{\mathrm{abc}}$ & $0.93^{\mathrm{ab}}$ & $1.0^{\mathrm{a}}$ & $0.93^{a b}$ & $\begin{array}{c}0.124 \\
(0.0001)\end{array}$ \\
\hline & AMI & AMP & CAR & CEF & CFT & CIP & CLO & GEN & NET & NIT & NOT & STM & $\begin{array}{c}\text { EEM } \\
(P)\end{array}$ \\
\hline Gram - & $1.0^{\mathrm{a}}$ & $1.0^{\mathrm{a}}$ & $1.0^{\mathrm{a}}$ & $1.0^{\mathrm{a}}$ & $1.0^{\mathrm{a}}$ & $0.6^{\mathrm{b}}$ & $1.0^{\mathrm{a}}$ & $1.0^{\mathrm{a}}$ & $1.0^{\mathrm{a}}$ & $0.8^{\mathrm{b}}$ & $1.0^{\mathrm{a}}$ & $1.0^{\mathrm{a}}$ & $\begin{array}{l}0.002 \\
(0.05)\end{array}$ \\
\hline
\end{tabular}

AMP: ampicilina, CEF: cefalotina, CFT: cefotaxima, CIP: ciprofloxacina, CLI: clindamicina, DIC: dicloxacilina, ERI: eritromicina, GEN: gentamicina, PEN: penicilina, STM: sulfametoxazol-trimetroprim, TET: tetraciclina, VAN: vacomicina, CLO: cloranfenicol, CAR: carbenicilina, NET: netilmicina, NIT: nitrofurantoína, NOT: norfloxacino y AMI: amikacina. EEM: error estándar de la media. Valores de la media con el mismo superíndice no son significativamente diferentes. Los datos porcentuales fueron transformados para ser analizados a través de la prueba exacta de Fisher.

A partir de las hisopados vaginales el $41.2 \%$ de las muestras presentaron crecimiento bacteriológico. Manes et al., 2013 reportaron 52\% de muestras positivas al aislamiento en cabras Saanen en etapa reproductiva, mientras que Penna et al., 2013 reportaron un $77 \%$ de muestras positivas en cabras Saanen en condiciones de anestro gestacional. Por otro lado, Oliveira et al., 2013 reportaron 100\% de aislamiento bacteriano en cabras anéstricas Toggenbourgh, mientras que Ababneh y Degfa 2006 reportaron 75\% de aislamiento en cabras Baladi post-parto. Estos diferentes resultados indican la alta variabilidad del aislamiento bacteriano que puede ser debido tanto a la raza, estado reproductivo y estado fisiológico. Esta investigación muestra que, en cabras criollas, sin una definición aparente de estacionalidad reproductiva, el aislamiento de la microbiota bacteriana aerobia no es mayor al $50 \%$. Se requiere de más estudios para relacionar el estado fisiológico y el perfil racial con el aislamiento bacteriológico.

En este estudio se muestra que la población bacteriana aerobia predominante en cabras criollas sanas fue bacterias GP (84.4\%) y en menor medida bacterias GN (15.6\%). Diversos estudios concuerdan con nuestros resultados. Manes et al., 2013 aislaron 77\% de bacterias GP en cabras Saanen antes de la inserción de esponja vaginal con $60 \mathrm{mg}$ de acetato medroxiprogesterona para la sincronización del estro; mientras que Penna et al., 2013 aislaron $71.3 \%$ de bacterias GP, siendo Staphylococcus coagulasa negativos (CoNS) las principales bacterias aisladas. Este hallazgo coincide con nuestro trabajo, ya que el mayor número de bacterias aisladas pertenecieron al género Staphylococcus spp. (31.2\%), aunado al aislamiento de S. chromogenes (6.3\%) y S. xylosus (3.1\%). Oliveira et al., 2013 también aislaron Staphylococcus spp. en 63.6\% de hisopados vaginales en 
cabras anéstricas. Estos hallazgos pueden indicar que el género Staphylococcus es habitante primario en la MV en cabras. No se ha reportado la presencia de vaginitis en estos animales asociado a este género bacteriano (Oliveira et al. 2013), tal como ocurre en otras especies (Deng et al., 2019; Shea et al., 2019), indicando que en estos hospedadores pueden ser patógenos oportunistas.

El segundo grupo bacteriano aislado de los hisopados vaginales fue Aerococcus spp. con un porcentaje de $21.9 \%$. Esta bacteria GP ha sido asociada a infecciones urinarias oportunistas en bovinos (Liu et al., 2019). Previamente se ha reportado su presencia en mucosa vaginal de cabras, sin signos de infección (Meekins et al., 2017). Esto podría indicar que, al igual que Staphyloccocus spp, el género Aerococcus es un habitante normal de la mucosa vaginal en cabras.

En proporción, los aislamientos de C. jeikeium y E. coli fueron similares (15.6\%). C. jeikeium, bacilo GP, ha sido relacionado con mastitis subclínica en ovejas (Queiroga, 2017). No existen reportes de la presencia de este bacilo en cabras, y con base a la frecuencia de aislamientos de esta bacteria en este estudio, es probable que sea parte de la MV autóctona de cabras criollas en el noreste mexicano. En contraste, E. coli es una enterobacteria ampliamente distribuida, es la principal bacteria que forma parte de la microbiota intestinal en animales domésticos (excepto aves). El aislamiento de esta enterobacteria en regiones anatómicas fuera del intestino está relacionado con infecciones patógenas y oportunistas (Gyles y Fairbrother, 2010). En rumiantes ha sido relacionada como causa de aborto e infecciones urogenitales (Sargison et al., 2007). En cabras esta enterobacteria se ha reportado tanto en ausencia de vaginitis como en procesos inflamatorios (Martins et al., 2009; Oliveira et al., 2013). La presencia de E. coli en este trabajo puede sugerir, por tanto, una colonización oportunista.

El aislamiento de $C$. renale puede representar un hallazgo incidental, ya que no ha sido reportado previamente como parte de la MV en cabras. Sin embargo, este microrganismo puede producir diversas infecciones urinarias en cabras y ovejas, aunque es poco común (Moore et al., 2010). Adicionalmente se ha aislado en vacas clínicamente sanas, comportándose como patógeno oportunista, produciendo cistitis, uretritis y pielonefritis (Yeruham et al., 2006), debido a su adaptabilidad ambiental (Moore et al., 2010). El aislamiento de $C$. renale en la mucosa vaginal de cabras criollas puede, al igual que $E$. coli, representar la colonización de una bacteria oportunista.

Finalmente, Streptococcus spp. se encontró en una proporción baja (3.1\%), comparado con los otros cocos GP. Penna et al., 2013 reportaron el aislamiento de estos agentes en $51.1 \%$ en hisopados vaginales, antes de la inserción de esponja vaginal, indicando que estas bacterias forman parte de la MV. Por otro lado, este género bacteriano se ha relacionado ampliamente como patógeno de cabras produciendo mastitis (Steward et al., 2017). No se ha reportado la presencia de vaginitis o infecciones urinarias a causa de 
especies de Streptococcus spp. Es probable que el hallazgo en este trabajo corresponda evidentemente a MV, tal como lo sugiere Penna et al., 2013.

\section{Susceptibilidad a quimioterapéuticos}

En este trabajo se mostraron diferentes perfiles de susceptibilidad a antibióticos, tanto para bacterias GP como GN. La diferencia de susceptibilidad entre estos dos grupos bacterianos (83.2\% de GP contra $95 \%$ de GN) debe ser tomado con reserva, ya que en las bacterias GN se aislaron en menor cantidad a partir de los hisopados. Sin embargo, es de hacer notar la alta resistencia de los aislamientos a la acción de los antibióticos, considerando que éstos son parte de la MV, y que por tanto, no han sido sometidos extensivamente a antibioterapia.

De los antibióticos probados eritromicina y tetraciclina mostraron ser completamente ineficaces contra los aislamientos GP, mientras que todos los antibióticos probados contra GN resultaron ineficaces, a excepción de ciprofloxacina y nitrofurantoína. Al respecto Oliveira et al., 2013 y Penna et al., 2013 consideran que el uso irrestricto de antibióticos en la promoción del crecimiento, así como en el tratamiento de animales jóvenes de enfermedades diarreicas y respiratorias, puede predisponer a la propagación de resistencia, tal como ha sido evidenciado para bacilos GN (Moghaddam et al., 2015).

Del perfil de resistencia en GP, $S$. chromogenes, $S$. xylosus, $C$. renale y Streptococcus spp. mostraron ser completamente susceptibles al menos a un antibiótico. Adicionalmente, los aislamientos del género Aerococcus y $C$. jeikum mostraron la mayor susceptibilidad probados ante dicloxacilina y, cefotaxima y ampicilina, respectivamente. De estos fármacos, únicamente ampicilina ha sido reportada por tener alta efectividad contra aislamientos bacterianos (principalmente contra Staphylococcus spp) de la mucosa vaginal, con porcentajes de 50 al 100\% (Suárez et al., 2006; Martins et al., 2009; Oliveira et al., 2013; Manes et al., 2013) lo cual pone de manifiesto la efectividad de este antibiótico para el tratamiento de las vaginitis cuya etiología sea bacterias GP. Por otro lado, la principal etiología de las vaginitis bacterianas en pequeños rumiantes son bacterias coliformes (Ababneh y Degefa, 2006; Martins et al., 2009; Oliveira et al., 2013). Con relación a ello, en los aislamientos de $E$. coli únicamente ciprofloxacina mostró el menor porcentaje de resistencia (60\%). Al respecto Oliveira et al., 2013 mostraron que la ciprofloxacina fue $100 \%$ eficaz en el control de los aislamientos de $E$. coli, procedentes de aislados vaginales de cabras; de la misma forma que Martins et al., 2009 mostraron $100 \%$ de efectividad en bacterias coliformes procedentes de aislados vaginales de ovejas. Esto puede demostrar la rapidez con la cual $E$. coli puede desarrollar resistencia a la ciprofloxacina, por lo que es muy importante crear la concientización tanto a productores como a clínicos veterinarios en el uso responsable de antibióticos. 


\section{CONCLUSIÓN}

La MV aerobia de las cabras criollas del municipio de Jaumave, Tamaulipas está compuesta principalmente por bacterias GP (población representada principalmente por el género Staphylococcus spp) y en menor medida por bacterias GN (Escherichia coli). El aislamiento bacteriológico de los hisopados vaginales representó el $41.2 \%$ de las muestras, indicando que otro tipo de bacterias (nutricionalmente exigentes) pudieran estar formando parte de la MV. La MV aerobia GP encontrada demostró ser altamente resistente a eritromicina, tetraciclina y vancomicina, mientras que los aislamientos GN fueron resistentes a la mayoría de los quimioterapéuticos evaluados, a excepción de criprofloxacina y nitrofurantoína (con un perfil de resistencia del $60 \%$ y $80 \%$, respectivamente). El alto porcentaje de resistencia encontrada en este trabajo pone de manifiesto la importancia de un uso responsable de antibióticos en la producción caprina extensiva.

\section{AGRADECIMIENTOS}

Al proyecto SAGARPA CONACYT 2017-02-291311 "Desarrollo y transferencia de pruebas diagnósticas para lentivirus y microorganismos causantes de aborto: Chlamydia spp., Brucella melitensis, Leptospira spp. y Coxiella burnetti, en ovinos y caprinos". Facultad de Medicina Veterinaria y Zootecnia de la Universidad Autónoma de Tamaulipas, al Laboratorio de Diagnóstico de la FMVZ-UAT y al personal técnico-administrativo.

\section{LITERATURA CITADA}

ABABNEH MM, Degefa T. 2006. Bacteriological findings and hormonal profiles in the postpartum Balady goats. Reproduction in Domestic Animals. 41(1):12-16. http://dx.doi.org/10.1111/j.1439-0531.2006.00638.x

ALVA-PÉREZ J, López-Corona LE, Zapata-Campos CC, Vázquez-Villanueva J, BarriosGarcía HB. 2019. Condiciones productivas y zoosanitarias de la producción caprina en el altiplano de Tamaulipas, México. Interciencia. 44(3):152-158. https://www.redalyc.org/jatsRepo/339/33958848008/33958848008.pdf

BARROW GI, Feltham RKA. 2004. Cowan and Steel's manual for identification of medical bacteria. 3rd Edition. ISBN 9780521543286

BELKAID Y, Bouladoux N, Hand TW. 2013. Effector and memory T cell responses to commensal bacteria. Trends in Immunology. 34(6):299-306. http://dx.doi.org/10.1016/j.it.2013.03.003

DENG L, Schilcher K, Burcham LR, Kwiecinski JM, Johnson PM, Head SR. 2019. Identification of key determinants of Staphylococcus aureus vaginal colonization. Mbio. 10 (06):e02321 http://dx.doi.org/10.1128/mBio.02321-19 
GIANNATTASIO-FERRAZ S, Laguardia-Nascimento M, Gasparini MR, Leite LR, Araujo FMG, de Matos Salim AC, de Oliveira AP, Nicoli JR, de Oliveira GC, da Fonseca FG, Barbosa-Stancioli EF. 2019. A common vaginal microbiota composition among breeds of Bos taurus indicus (Gyr and Nellore). Brazilian Journal of Microbiology. 50(4):1115-1124. http://dx.doi.org/10.1007/s42770-019-00120-3

GYLES CL, Fairbrother JM. 2010. Escherichia coli En. Pathogenesis of bacterial infections in animals. Pp. 207-308. ISBN 978-0-8138-1237-3

HENDERSON G, Cox F, Ganesh S, Jonker A, Young W, Global Rumen Census Collaborators, Janssen PH. 2015. Rumen microbial community composition varies with diet and host, but a core microbiome is found across a wide geographical range. Scientific Reports. 5(October):14567. http://dx.doi.org/10.1038/srep14567

HOMBACH M, Böttger EC, Ross M. 2013. The critical influence of the intermediate category on interpretation errors in revised EUCAST and CLSI antimicrobial susceptibility testing guidelines. Clinical Microbiology and Infection. 19(2):E59-E71. https://www.clinicalmicrobiologyandinfection.com/article/S1198-743X(14)60256-1/fulltext

HUMPHRIES RM, Ambler J, Mitchell SL, Castanheira M, Dingle T, Hindler JA, Koeth L, Sei K, on behalf of the CLSI Methods Development and Standardization Working Group of the Subcommittee on Antimicrobial Susceptibility Testing. 2018 CLSI methods development and standardization working group best practices for evaluation of antimicrobial susceptibility tests. Journal of Clinical Microbiology. 56(4):e01934-17. https://jcm.asm.org/content/56/4/e01934-17.long

INEGI (Instituto Nacional de Estadística y Geografía). 2010. Compendio de información geográfica municipal $2010 \quad$ Jaumave. http://www3.inegi.org.mx/contenidos/app/mexicocifras/datos_geograficos/28/28017.pdf

LIU G, Yin J, Han B, Barkema HW, Shahid M, de Buck J, Cobo ER, Kastelic JP, Gao J. 2019. Adherent/invasive capacities of bovine-associated Aerococcus viridans contribute to pathogenesis of acute mastitis in a murine model. Veterinary Microbiology. 230(November 2018):202-211. http://dx.doi.org/10.1016/j.vetmic.2019.02.016

MANES J, Fiorentino MA, Hozbor F, Paolicchi F, Alberio R, Ungerfeld R. 2013. Changes in the aerobic vaginal bacteria load and antimicrobial susceptibility after different oestrous synchronisation treatments in goats. Animal Production Science. 53(6):555-559. http://dx.doi.org/10.1071/AN12191 
MANES J, Fiorentino MA, Martino SS, Ungerfeld R. 2018. Changes in the vaginal microbiota in ewes after insertion of intravaginal sponges at different stages of the oestrous cycle. Livestock Science. 208(November 2017):55-59. https://doi.org/10.1016/j.livsci.2017.11.023

MARTINS G, Figueira L, Penna B, Brandão F, Varges R, Vasconcelos C, Lilenbaum W. 2009. Prevalence and antimicrobial susceptibility of vaginal bacteria from ewes treated with progestin-impregnated intravaginal sponges. Small Ruminant Research. 81(23):182-184. https://doi.org/10.1016/j.smallrumres.2008.12.003

MAURER FP, Courvalin P, Böttger EC, Hombach M. 2014. Integrating forecast probabilities in antibiograms: a way to guide antimicrobial prescriptions more reliably? $\begin{array}{llll}\text { Journal of Clinical } & \text { Microbiology. }\end{array}$ https://jcm.asm.org/content/52/10/3674.

MAYNARD CL, Elson CO, Hatton RD, Weaver CT. 2012. Reciprocal interactions of the intestinal microbiota and immune system. Nature. 489(7415):231-41. https://doi.org/10.1038/nature11551

MEEKINS JM, Apley MD, Lubbers B, Peddireddi L, Rankin AJ. 2017. Evaluation of conjunctival bacterial flora in a herd of goats in the Midwestern United States. Veterinary Ophthalmology. 20(1):40-45. https://doi.org/10.1111/vop.12348

MOGHADDAM, MJM, Mirbagheri AA, Salehi Z, Habibzade SM. 2015. Prevalence of class 1 integrons and extended spectrum beta lactamases among multi-drug resistant Escherichia coli isolates from north of Iran. Iranian Biomedical Journal. 19(4): 233-239. https://doi.org/10.7508/ibj.2015.04.007

MOORE R, Miyoshi A, Pacheco LGC, Seyffert N, Azevedo V. 2010. Corynebacterium and Arcanobacterium. En. Pathogenesis of bacterial infections in animals. Pp. 133-147. ISBN 978-0-8138-1237-3.

OLIVEIRA JK, Martins G, Esteves LV, Penna B, Hamond C, Fonseca JF, Rodrigues AL, Brandão FZ, Lilenbaum W. 2013. Changes in the vaginal flora of goats following a shortterm protocol of oestrus induction and synchronisation with intravaginal sponges as well as their antimicrobial sensitivity. Small Ruminant Research. 113(1):162-166. https://doi.org/10.1016/j.smallrumres.2013.02.011

OTERO C, Saavedra L, Silva de Ruiz C, Wilde O, Holgado AR, Nader-Macías ME. 2000. Vaginal bacterial microflora modifications during the growth of healthy cows. Letters in Applied Microbiology. 31(3):251-254. https://doi.org/10.1046/j.1365-2672.2000.00809.x 
PASCALE A, Marchesi N, Marelli C, Coppola A, Luzi L, Govoni S, Giustina A, Gazzaruso C. 2018. Microbiota and metabolic diseases. Endocrine. 61(3):357-371. https://doi.org/10.1007/s12020-018-1605-5

PENNA B, Libonati H, Director A, Sarzedas AC, Martins G, Brandão FZ, Fonseca J, Lilenbaum W. 2013. Progestin-impregnated intravaginal sponges for estrus induction and synchronization influences on goats vaginal flora and antimicrobial susceptibility. Animal Reproduction Science. 142(1-2):71-74.

https://doi.org/10.1016/j.anireprosci.2013.09.006

PINOS-RODRÍGUEZ JM, Gómez-Ruiz WJ, Aguirre-Rivera JR, García-López JC, ÁlvarezFuentes G. 2015. Profitability of goat production in the Mexico highlands. Outlook on Agriculture. 44(3):223-233. https://doi.org/10.5367/oa.2015.0214

QUEIROGA MC. 2017. Prevalence and aetiology of sheep mastitis in Alentejo region of Portugal. Small Ruminant Research. 153(June):123-130. https://doi.org/10.1016/j.smallrumres.2017.06.003

SALINAS-GONZÁLEZ H, Valle Moysen ED, de Santiago Miramontes MA, Véliz Deras FG, Maldonado Jáquez JA, Vélez Monroy I, Torres Hernández D, Isidro Requejo LM, Figueroa Viramontes U. 2016. Análisis descriptivo de unidades caprinas en el suroeste de la región lagunera, Coahuila, México. Interciencia. 41(11):763-768. https://www.redalyc.org/articulo.oa?id=33948191006

SARGISON ND, Howie F, Mearns R, Penny CD, Foster G. 2007. Shiga toxin-producing Escherichia coli as a perennial cause of abortion in a closed flock of Suffolk ewes. Veterinary Record. 160(25):875-876. https://doi.org/10.1136/vr.160.25.875

SHEA EK, Berent AC, Weisse CW. 2019. Vesicovaginal fistula in a dog with urinary incontinence. Journal of the American Veterinary Medical Associaton. 255(4):466-470. https://doi.org/10.2460/javma.255.4.466

SIAP (Servicio de Información Agroalimentaria y Pesquera). SIACON (Sistema de Información Agrolimentaria de Consulta). 28 de junio de 2019. https://www.gob.mx/siap/documentos/siacon-ng-161430

STEWARD KF, Robinson C, Holden MTG, Harris SR, Ros AF, Pérez GC, Baselga R, Waller AS. 2017. Diversity of Streptococcus equi subsp. zooepidemicus strains isolated from the Spanish sheep and goat population and the identification, function and prevalence of a novel arbutin utilisation system. Veterinary Microbiology. 207(May):231238. https://doi.org/10.1016/j.vetmic.2017.06.020 
SUÁREZ G, Zunino P, Carol H, Ungerfeld R. 2006. Changes in the aerobic vaginal bacterial mucous load after treatment with intravaginal sponges in anoestrous ewes. Small Ruminant Research. 63(1-2):93-43.

https://www.sciencedirect.com/science/article/abs/pii/S0921448805000386

YERUHAM I, Elad D, Avidar Y, Goshen T. 2006. A herd level analysis of urinary tract infection in dairy cattle. The Veterinary Journal. 171(1):172-176. https://doi.org/10.1016/j.tvjl.2004.04.005 